\title{
LA RECEPCIÓN DE LA CREACIÓN DE RIESGOS NO PERMITIDOS EN EL DERECHO CHILENO, COMO CRITERIO DE IMPUTACIÓN OBJETIVA, ¿PUEDE DISTINGUIRSE DE LA CULPA?
}

THE RECEPTION OF THE CREATION OF UNAUTHORIZED RISKS IN CHILEAN LAW, AS A CRITERION FOR OBJECTIVE IMPUTATION, CAN IT BE DISTINGUISHED FROM FAULT?

Cristián Aedo Barrena*

\section{RESUMEN}

El presente trabajo explora las confluencias entre causalidad y culpa. Una vez que se considera que la causalidad no se satisface solo con criterios materiales o fácticos, y que debe ser auxiliada con criterios normativos, la doctrina ha planteado la confluencia de la culpa y la creación de riesgos no permitidos, criterio normativo de la imputación objetiva, de origen alemán. A partir de dicho análisis se propone distinguir entre causalidad comisiva y omisiva y se propone que, en ambos casos, la culpa opera como mecanismo de auxilio de la causalidad.

Palabras claves: culpa; causalidad; imputación objetiva; omisión.

\section{ABSTRACT}

This paper explores the confluences between causality and fault. Once it is considered that causality is not satisfied only with material or factual

* Doctor en Derecho por la Universidad de Deusto, Bilbao, España. Profesor de Derecho Romano y Derecho Civil en la Facultad de Derecho de la Universidad Católica de la Santísima Concepción, Chile. Correo electrónico: caedo@ucsc.cl.

Este artículo forma parte del proyecto Fondecyt Regular, número 1191729, denominado "Delimitación de regímenes de responsabilidad civil. Elementos y factores a considerar para una parcial unificación”, del cual el autor es investigador principal.

Recepción: 2020-06-15; aceptación: 2020-10-04. 
criteria, and that it must necessarily be assisted with normative criteria, the doctrine has raised the confluence of fault and the creation of unauthorized risks, normative criterion of the imputation objective, of German origin. Based on this analysis, it is proposed to distinguish between commissive and omisive causality and it is proposed that, in both cases, fault operates as a mechanism to aid causality.

Keywords: fault; causality; objective imputation; omission.

\section{INTRODUCCIÓN: CÓMO DELIMITAR EL PROBLEMA}

En este artículo examinaremos la recepción de la imputación objetiva en el derecho chileno, deteniéndonos, en particular, en la creación de riesgos no permitidos. Argumentaremos que la culpa no puede separarse del análisis de la creación de riesgos no permitidos, que se configura, como la culpa, a partir de un deber de cuidado. El análisis de las funciones de la causalidad, en la teoría de la imputación objetiva, y la confluencia entre la teoría y la culpa, conducirá a ofrecer conclusiones preliminares relativas al establecimiento del vínculo causal, debiendo distinguirse, para tal efecto, entre las conductas comisivas y omisivas.

Analizaremos, por consiguiente, la consagración de la imputación objetiva en el derecho civil y su adopción en la dogmática chilena, fundadas en las ideas de Fernando Pantaleón y Luis Díez-Picazo, que han servido de modelo para su construcción por la dogmática.

No es propósito del presente trabajo, detenernos en la justificación de la imputación objetiva y su traslado al derecho de daños. En esta esfera, puede proponerse, como debate, las bases sobre las cuáles un régimen de responsabilidad civil debe construirse $\mathrm{y}^{1}$, desde ahí examinar si, tanto la teoría como sus criterios, pueden ser trasladables a la responsabilidad civil ${ }^{2}$.

\footnotetext{
${ }^{1}$ Para el problema del fundamento de la responsabilidad civil, AEdo (2019), p. 331 y ss.

${ }^{2}$ La teoría de la imputación se presenta como un nuevo sistema penal. A diferencia de las tesis ontológicas (causalista o finalista), la imputación objetiva pretende la reconstrucción desde el plano valorativo del tipo. Como afirma Yesid Reyes: "En síntesis, puede afirmarse que el contenido de una conducta 'injusta' es labor de una teoría de la imputación objetiva, mientras el desarrollo de lo que atañe a su aspecto individual incumbe a una teoría de la imputación subjetiva”. ReYes (2005), p. 68. Como indica Frisch (2004), pp. 32; 38-41, la teoría se ha transformado en una especie de megateoría con la que bajo la rúbrica de imputación se busca resolver problemas de injusto. Agrega: "la teoría de la imputación o no imputación del resultado era, para una concepción del injusto que acentuaba el desvalor de resultado, el instrumento adecuado para discernir entre injusto y no injusto, y además bastaba para tal concepción". En suma, debemos tener también en cuenta que
} 
Con todo, el presente trabajo arranca del dato que, algunos criterios de imputación objetiva, en especial los propuestos por Claus Roxin y Günter Jakobs, son los que han sido acogidos, para el ámbito hispanoamericano, en España y luego, trasladados al derecho chileno, como mecanismo y solución de problemas causales. En parte, pensamos, que dicha adopción se vio favorecida en cuanto la tesis de Claus Roxin fue pensada para los delitos imprudentes ${ }^{3}$.

\section{LA CAUSALIDAD COMO PROBLEMA EN EL DERECHO:} SUS FUNCIONES

El juicio de responsabilidad implica distinguir dos momentos: por un lado, determinar la concurrencia de los requisitos necesarios para la configuración de la causalidad y, por el otro lado, la determinación de los daños de los que responde el o los autores ${ }^{4}$.

¿Qué papeles cumple la causalidad en el juicio de responsabilidad civil? De acuerdo con una perspectiva, la causalidad interviene tanto para determinar el radio de los responsables como para delimitar los daños de los que se responde ${ }^{5}$. De acuerdo con otra tesis, que arranca de la idea de imputación de Georg Hegel (y la tesis de la imputación objetiva), el juicio de causalidad debe separarse del de imputación. Con el primero, de carácter fáctico, debe determinarse (o descartarse), el círculo de respon-

la teoría de la imputación objetiva se encuentra en plena formación, obedece a criterios, fines y funciones ajenos a los que tradicionalmente se les reconoce a la responsabilidad civil (pues se construye desde la prevención político-criminal), y ello es sin perjuicio de las fundamentaciones filosóficas de la teoría, que, sin duda alguna, deben tenerse en cuenta. Para el tratamiento general de la teoría pueden citarse algunas obras generales de la dogmática penal. Por todos, sin que sea exhaustiva la cita, véase ANARTE (2002), p. 123 y ss.; Bacigalupo (2004), p. 264 y ss.; Cerezo (2008), p. 405 y ss.; Frisch (1995); Jescheck y Weigend (2002), p. 307 y ss. Para las discusiones y críticas a la teoría, ajena a los propósitos de este trabajo, véase FeIjoo (2018), pp. 24-48. Véase también, PELÁEz (2018), pp. 302-303. En la responsabilidad civil, para la controversia dogmática en torno a la imputación objetiva, véase nuestro trabajo AEdo (2017a), pp. 350-351.

${ }^{3}$ Para el análisis de esta cuestión, véase Corcoy (1994), p. 42. También véase Feijoo (2018), pp. 24-30. Un detallado análisis de la tesis de Claus Roxin, de las variaciones introducidas por sus discípulos y la teoría de Günter Jakobs, en ANARTE (2002), pp. 125-151.

${ }^{4}$ SAn Martín (2016), p. 13.

${ }^{5}$ La doctrina chilena tradicional es unánime en el sentido que la causalidad interviene en la extensión de la reparación, al considerar que el daño debe ser directo. Véase Alessandri (2005), p. 395. En el mismo sentido, Barcia (2010), p. 259; Dítz Schwerter (1998), pp. 71-73. Para el derecho comparado, en España, Dítz-Picazo (2007), tomo v, p. 357 y, en Francia, Mazeaud y Tunc (1977), pp. 2, 270. Véase también, QuÉzel-Ambrunaz (2010), pp. 11448 y Malaurie, Aynés Stoffel-Munck (2015), p. 55. 
sables, en tanto que los problemas de imputación permitirían distinguir los daños indemnizables ${ }^{6}$.

Ahora bien, con independencia de estas posiciones ${ }^{7}$, hay acuerdo en que no basta con un test fáctico, para la determinación causal ${ }^{8}$. En efecto, aun cuando la causalidad sea una categoría ontológica y un componente gnoseológico en la filosofía y en las ciencias ${ }^{9}$, para el derecho, es necesario

${ }^{6}$ Pantaleón (1991), tomo iI, p. 1561 y ss. Para Fernando Pantaleón debe distinguirse de las cuestiones causales, destinadas a delimitar el círculo de responsables, del problema normativo de la imputación objetiva, que persigue la determinación de los perjuicios resarcibles. Para el derecho chileno, véase Prevot (2010), p. 164. Aunque se ha afirmado también que la causalidad jurídica cumple ambos papeles descritos, véase BELvedere (2006), pp. 13-16.

${ }^{7}$ Como afirma José María Peláez Mejía, para las relaciones entre causalidad e imputación objetiva, en el campo penal, se han elaborado las siguientes teorías: "No obstante, en torno a las relaciones entre causalidad e imputación objetiva se encuentran al menos las siguientes posturas: (i) aquellos para quienes la imputación objetiva reemplaza completamente la determinación del nexo causal como elemento independiente en la configuración de la tipicidad; (ii) los que afirman que la causalidad como elemento del tipo penal objetivo no ha desaparecido, sino que simplemente se ha integrado a la imputación objetiva como uno de sus escalones de estructuración internos; (iii) quienes declaran que la causalidad en los delitos de resultado es simplemente un presupuesto necesario y previo a la determinación de la imputación objetiva pero insuficiente para la afirmación del tipo penal objetivo, por lo que su coexistencia en la configuración de este no resultaría problemática, sino por el contrario indefectible; y (iv) los que abogan por la desaparición de la imputación objetiva y el renacimiento de la causalidad como criterio único de atribución utilizando para ello nuevas teorías provenientes de otras disciplinas del conocimiento que permitan determinar el nexo causal, ya que la mayoría de los casos que resuelve la imputación objetiva son en realidad casos propios la de la causalidad". Véase Peláez (2018), pp. 298-299.

${ }^{8}$ Este fue, sin embargo, el enfoque de la codificación. Como señalan Guido Alpa y Mario Bessone, tanto en la experiencia francesa y gran parte de la codificación que siguió sus raíces, el nexo de causalidad aparecía como un elemento extraño a la ilicitud, siendo un simple componente material que vinculaba la conducta ilícita con un resultado dañoso, a diferencia de la experiencia del Common Law, en cuyo seno la relación de causalidad fue siempre un poderoso instrumento para discriminar los intereses merecedores de tutela. Véase Alpa y Bessone (1976), p. 280. Para la tradición codificada, por todos, Ripert y Boulagner (1965), pp. 106; 110. Ello no quiere decir que no haya importantes esfuerzos, tanto desde la filosofía del derecho como de la dogmática, por construir un criterio de causalidad desde la perspectiva científica. Para esta cuestión, HART \& HonOrÉ (1990), p. 105 y ss., para el test but-for. Y, WRITGH (1985), p. 1788 and next; WRITGH (1988), p. 1021 and next, para el test NESS, materia ajena a nuestro interés.

${ }^{9}$ Este paradigma se ha reestructurado a partir de la teoría de la relatividad. Más allá de la explicación científica de la teoría, esta, al unir el tiempo y el espacio, rompe toda nuestra concepción previa del tiempo, que ahora no es absoluto y vuelve la ciencia hacia viejos problemas filosóficos y espirituales: ¿hay un ahora?, ¿ por qué la causalidad se mueve en la dirección que observamos? La tesis del enfoque entrópico, es decir, aquella que nos explica la flecha del tiempo hacia el futuro (y, por consiguiente, nos permite encadenar los fenómenos en causa-efecto), en términos generales, puede expresarse de la siguiente 
amoldar ciertos criterios. El enfoque científico y del derecho, son distintos. Mientras el primero se preocupa de determinar leyes generales, para grupos de situaciones, el derecho debe resolver la conexión fáctica, tratándose de un hecho concreto ${ }^{10}$. En este sentido, como indica Marco Capecchi, en el ámbito jurídico, la causalidad no es un dato unitario para cada hipótesis de responsabilidad civil, sino un criterio de imputación que varía según la disposición normativa ${ }^{11}$. Por eso, como veremos, se considera que a una causalidad material o fáctica debe complementarse con un juicio normativo o de juridicidad, sea que este juicio delimite los responsables o, por el contrario, se trate de un juicio valorativo que tiene relación con los daños reclamables ${ }^{12}$, pretendiéndose con ello solucionar los problemas que para la dogmática presenta la teoría de la equivalencia de las condiciones ${ }^{13}$.

manera: pasado y futuro se definen como los sentidos temporales hacia donde la entropía decrece o aumenta respectivamente, haciendo depender la asimetría y direccionalidad temporal del Segundo Principio de la Termodinámica. El enfoque entrópico cae en cierta circularidad: presupone nuestras intuiciones temporales como, por ejemplo, la relación anterior- posterior. El núcleo del problema es que el argumento termodinámico no debería presuponer que los estados de baja entropía son anteriores a los estados de alta entropía, como así tampoco sostener que esta aumenta o disminuye: de lo único que da cuenta es de que existe un gradiente entrópico. Sobre el problema, véase Drapkin (1943), pp. 5-6 y, Roxin (1997), p. 346; CASTALdo (2008), pp. 27-38. Para el problema causal del tiempo, LÓPEZ (2018), p. 85 y ss.

${ }^{10}$ Véase Hart y Honoré (1990), pp. 10-12. En el mismo sentido Quézel-Ambrunaz (2010), pp. 59-60; 176-177.

${ }^{11}$ CApecchi (2012), pp. 6-7.

${ }^{12}$ Véase, Mazeaud y Tunc (1977), pp. 1-2; 40-41: En el mismo sentido, QuÉzelAmbrunaz (2010), pp. 234-235; Viney Et Jourdain (2013), p. 239, quienes sostienen que, aunque causalidad y culpa deben diferenciarse, la primera supone un hecho culposo del autor del daño. Es una aproximación común por parte de varios autores europeos. Véase, por ejemplo, De Ángel (1993), pp. 814-815, quien ubica el problema en la relación de causalidad, pero definida sobre la base de la culpa (considerada de modo análogo a aquella en la que incurre el autor del daño); Castronovo (2018), pp. 349-350; Trimarchi (2017), pp. 453-454. No puede abordarse aquí, la discusión relativa a los criterios normativos de la causalidad o si es posible referirse a una causalidad jurídica. Para este problema, en el ámbito penal, véase, por todos, WELzel (2002), p. 51. Para el problema de una causalidad jurídica, separada de otra, ontológica, remitimos a nuestro trabajo, AEDo (2006), p. 271 y ss. y en AEDo (2018), p. 371 y ss.

${ }^{13}$ Roxin (1997), pp. 350-351, pone de relieve que es una doctrina inútil, que no aporta nada para comprender la causalidad, pero que, además, se trata de una fórmula que puede inducir a error y pone dos ejemplos: uno de causalidad hipotética y otro de causalidad alternativa. Véase también, in extenso, CASTALDO (2008), pp. 21-27. Karl Engish le reprocha utilidad, en el sentido de que los cursos causales deben ser descritos o conocidos antes para poder eliminarlos mentalmente. Véase ENGISCH (2008), p. 21. En un sentido similar, Anarte (2002), pp. 29-40; Barros (2020), pp. 444-445; Reyes (2005), pp. 229-234. En el Common Law se ha planteado el mismo problema. La jurisprudencia anglosajona utilizó el denominado test but for, muy similar a la doctrina de la equivalencia de las condiciones, 


\section{LA RECEPCIÓN DE LA IMPUTACIÓN OBJETIVA}

EN LA RESPONSABILIDAD CIVIL

La denominada teoría de la imputación objetiva tiene su origen en el eminente civilista Karl Larenz, quien intenta distinguir los problemas de causalidad, de aquellos de imputación ${ }^{14}$. Como explica Paz de la Cuesta, Karl Larenz fundamenta la responsabilidad objetiva en la voluntad capaz de dirigir y prever el curso causal, no siendo una teoría causal, sino una de imputación ${ }^{15}$.

La construcción trasplantada al campo civil y adoptada en Chile, ha sido la teoría desarrollada por Claus Roxin y Günter Jakobs ${ }^{16}$. Según el

para comprobar la denominada causation in fact. Con el tiempo, sin embargo, se han ido incorporando nuevos criterios jurisprudenciales. Sobre este tema, véase el trabajo de Honoré (2002), p. 94 ss. También publicado en Owen (1997), p. 363 and next; Wrigth (1988), pp. 1020-1022 y WRIGTH (2008), p. 1303. En un sentido similar, CAPECCHI (2012), pp. 160-162. Quézel-Ambrunaz (2010), pp. 40-41, explica algunos de los correctivos a la teoría, como el principio de exclusión de condiciones irrelevantes, la restricción de daños de un determinado tipo, entre otros.

${ }^{14}$ Larenz (1958), tomo I, pp. 200-201. Sabido es que Karl Larenz construye su teoría sobre la base de la filosofía de la imputación de Georg Hegel. No podemos detenernos, desde luego, en la formación e historia de la imputación objetiva, pero para esta cuestión 122 véase el trabajo de AnARTe (2002), pp. 105-118 y Reyes (2005), p. 51 y ss. En cuanto a su origen filosófico, Yesid Reyes indica que el presupuesto de dicha teoría es el concepto de: "imputación acuñado por Hegel, con arreglo al cual sólo se puede hablar de imputación en el caso que la consecuencia, la mutación del mundo exterior puede atribuirse a la obra del autor. Este principio se traduciría en el principio de la auto-responsabilidad, conforme al cual sólo se responde de la propia conducta”.

En cuanto a su génesis sistemática, como señala Frisch (1995), pp. 30-31, por un lado, se buscó sustituir la teoría de la equivalencia por una causalidad jurídica. El concepto natural debería quedar desplazado por un concepto jurídico más amplio. Esto se desarrolló por una serie de vías: atendiendo a la última condición, o la condición que imprime la dirección hacia el resultado, o la más eficaz o la adecuada. Otros intentos propusieron sustituir la teoría de la equivalencia -no por otra causalidad jurídica-, sino basados en esta perspectiva, es decir, agregando a la equivalencia un enjuiciamiento adicional, normativo, proponiendo vías de descartes. Estas vías de descarte normativo operaron a través de la teoría de la relevancia, cuyo más importante representante fue Edmund Mezger: los cursos que no parecen encajar en los tipos serían irrelevantes. Sin embargo, los precedentes de la expresión son muy anteriores. El primero que se refiere a reglas de imputación es Samuel Pufendorf. Véase HRuscka (2005), pp. 55-56 el primer axioma sobre la imputación es formulado por el filósofo del derecho e historiador alemán en Elementa, con arreglo al cual puede imputarse a una persona aquellos que de los que es su causa y está a su alcance. Para el tratamiento de Samuel Pufendorf, véase el análisis histórico de AEdo (2018), pp. 173-178. Para los precedentes en el derecho penal del siglo Xx, véase ANARTE (2002), p. 103 y ss.

${ }^{15}$ De la Cuesta (1996), p. 145.

${ }^{16}$ En la responsabilidad civil, la teoría ha recibido acogida plena en España, a diferencia de otras tradiciones continentales, como en Francia o Italia. Véase, sobre esta cuestión, AEdo (2018), p. 394 y ss. 
primero, un resultado causado por el agente solo se puede imputar si la conducta del autor ha creado un peligro para el bien jurídico no cubierto por el riesgo permitido y ese peligro también se ha realizado en el resultado concreto. Agrega:

"Mientras que la falta de creación de peligro conduce a la impunidad, la falta de realización del peligro en una lesión típica del bien jurídico sólo tiene como consecuencia la ausencia de consumación [...]. En resumen, pues, se puede decir que la imputación al tipo objetivo presupone la realización de un peligro creado por el autor y no cubierto por un riesgo permitido dentro del alcance del tipo"17.

Además de la regla general, Claus Roxin enuncia criterios complementarios que permiten especificar la regla general señalada, entre los que encontramos la exclusión disminución de riesgo y la falta de creación de peligro y exclusión en casos de riesgo permitido ${ }^{18}$.

Conforme a Günter Jakobs, desde esta lectura, ahora normativa, se arranca de la premisa de que todas las personas cumplen un papel social, es decir, toca a las personas administrar un determinado segmento de la vida social y, en consecuencia, la cuestión está en determinar de qué modo se apartan de ese papel exigido ${ }^{19}$.

${ }^{17}$ Roxin (1997), pp. 363-364. Se debe considerar, en todo caso, que el planteamiento de Claus Roxin ha sido vivamente debatido en el campo penal: las razones son variadas, pero pueden considerarse tres tipos de objeciones. La primera es que, en tanto el criterio determina una órbita de riesgos en abstracto, se ha exigido una cierta trascendencia del riesgo para considerar la creación del riesgo como ilícito, pero, en palabras de Bernardo Feijoo, es una posición difícil de precisar si se atiende a riesgos concretos. Por ejemplo, en el caso que alguien cause un daño conduciendo a $56 \mathrm{~km}$ por hora, en una zona de $50 \mathrm{~km}$, acreditándose que el daño no pudo haberse evitado, aun ajustándose a la norma. También se ha criticado la extensión indebida que la norma plantea al principio de legalidad. Y, en tercer lugar, se ha criticado su extensión a determinados tipos penales: en principio, a delitos dolosos, cuando Claus Roxin considera el criterio para delitos imprudentes; y, la aplicabilidad del criterio a los problemas de comisión por omisión. A esta última cuestión, nos referiremos más adelante. Para las críticas, véase el citado FeIjoo (2018), pp. 49-59. Sobre estos problemas, véase también FrISCH (2014), p. 56 y ss.

${ }^{18}$ Roxin (1997), pp. 365-366; 371, 373.

${ }^{19}$ Jakовs (1997), p. 25. Es posible advertir, en el denominado principio de confianza, un criterio más seguro para ser aplicado, tanto a la responsabilidad civil, como a la penal. FEIJOO (2018), pp. 184-186, sostiene que, en un Estado democrático de derecho, el reconocimiento del otro, de los conciudadanos, en tanto iguales y, por consiguiente, de la libertad ajena, establece el principio de autorresponsabilidad. Para fundar el criterio de autocuidado, entonces, se debe estar a la idea de libertad, en la formulación de Georg Hegel, cuya normativización se ha trasladado a como fundamento a la responsabilidad civil, y a la penal. 
Como hemos dicho, en el ámbito continental europeo, la doctrina ha sido adaptada a la dogmática civil por Fernando Pantaleón en España, quien partiendo del supuesto que se trata de una cuestión de imputación jurídica y no de determinar naturalísticamente cuando una conducta es causa de un daño, propone una serie de criterios de imputación, entre ellos:

a) el riesgo general de la vida ${ }^{20}$;

b) el incremento del riesgo ${ }^{21}$;

c) el principio de confianza ${ }^{22}$;

d) la prohibición de regreso ${ }^{23}$ y

e) el fin de protección de la norma ${ }^{24}$, entre otros.

${ }^{20}$ Tanto en el campo penal como en el civil, se afirma que la vida social supone riesgos, no formando parte del papel de los ciudadanos eliminar todos los riesgos para los demás. Para el derecho penal, JAKOBs (1997), pp. 28-29, sostiene que la sociedad tiene un margen de riesgo permitido o tolerado en la vida social. Para Roxin (1997), pp. 363-364, en la denominada teoría de la imputación objetiva, un resultado causado por el agente solo se puede imputar si la conducta del autor ha creado un peligro para el bien jurídico no cubierto por el riesgo permitido y ese peligro también se ha realizado en el resultado concreto. Para el derecho civil, aceptan el mismo criterio, Díez-Picazo (2007), p. 343, Pantaleón (1991), p. 1591. Para el caso chileno Barros (2020), p. 402.

${ }^{21}$ Según las palabras de Fernando Pantaleón: "No toda conducta que crea el riesgo de 124 lesión de los bienes de los demás puede ser calificada de negligente. Por razones fáciles de comprender, todo ordenamiento jurídico considera correcta la realización de actividades más o menos peligrosas, en atención a la mayor o menor utilidad social de las mismas y la mayor o menor coste social de las medidas de reducción del riesgo. Una conducta sólo es negligente cuando sobrepasa los límites del riesgo que, a la luz de aquellos datos, el ordenamiento estima aceptable o tolerable; cuando sobrepasa, por emplear la terminología al uso, los límites del riesgo permitido”. Pantaleón (1991), p. 1561.

${ }^{22}$ Según este principio, como afirma Jakobs (1997), p. 30, si alguien genera una situación inocua, puede confiar en que otro cumplirá con las funciones derivadas de su responsabilidad; en segundo término, se puede dirigir a que una determinada situación preexistente haya sido preparada de modo correcto por el tercero, de manera que quien hace uso de ella, cumpliendo sus deberes, no es responsable. Le sigue, Dítz-PicAzo (1999), p. 344. Como afirma PIÑA (2005), pp. 55; 57, quien se desempeña en una actividad lucrativa, como un empresario, debe conducirse con el principio normativo de la confianza, en el sentido que: "...no tiene que contar con que su conducta produzca un resultado prohibido debido al comportamiento inadecuado de otro".

${ }^{23}$ Con este criterio se propone negar la imputación objetiva del daño cuando en el proceso causal dañoso, puesto en marcha por el demandado, ha sobrevenido una conducta dolosa o gravemente imprudente de un tercero, salvo que dicha conducta se haya visto significativamente favorecida por la actuación del demandado o, con más claridad, sea una de aquellas que la norma de cuidado infringida tenía la finalidad de prevenir. Ha formulado el criterio, en este sentido, Jakoвs (1997), pp. 31-32, seguido por Díez-PicAzo (1999), p. 344. Véase también De ÁngEl (2014), pp. 45-46.

${ }^{24}$ En este caso, no pueden ser objetivamente imputados a la conducta del autor del daño, aquellas infracciones que recaigan fuera del ámbito de protección de la norma cuya violación se invoca. Han sostenido este criterio, entre otros, PANTALEÓn (1991), p. 1987; 
Como indica Juan Alberto Piña, el giro normativo se encuentra determinado por la creación del riesgo permitido, cuya delimitación queda entregada a la esfera de la infracción del deber de cuidado. Según el autor, la determinación de los roles sociales, supone que quien no se encuentra en condiciones de alcanzar cierto estándar en la determinación en el desarrollo de una actividad, debe abstenerse de realizar las conductas que implican dicho estándar ${ }^{25}$. Sin duda alguna este principio convive con otro, desarrollado en el terreno de la imputación objetiva, en el campo del derecho penal, que establece el criterio de que si la víctima es responsable, resulta inadecuado establecer prohibiciones en las actuaciones de terceros, pues la víctima, en principio, puede cuidar sus propios bienes ${ }^{26}$, mientras que en responsabilidad civil la doctrina se refiere a una carga de la víctima y no de un deber que impide el autodaño, afirmándose la exclusión de responsabilidad desde el principio de autorresponsabilidad ${ }^{27}$. En términos más precisos, Luis Díez-Picazo entiende que si en la configuración de un contacto social el control de la situación corresponde a la víctima, deben imputarse a ella las consecuencias lesivas y no al supuesto autor ${ }^{28}$.

En Chile, la ha acogido la mayor parte de la doctrina. Tomemos nota de dos ejemplos. Para Hernán Corral, la causalidad debe ser determinada tanto fáctica como normativamente. La teoría de la equivalencia de las condiciones y su test de la supresión mental hipotética, permite determinar cuando un acto humano no puede considerarse causal por fallas la conexión natural y física entre el comportamiento humano y el efecto dañoso. Valen sus resultados para excluir la relación de causalidad. Sin embargo, el test no permite determinar cuáles son las condiciones que deben incluirse como causas, ni tampoco resulta útil cuando no existe experiencia o conocimientos acumulado sobre la incidencia del factor en

Díez-Picazo (1999), p. 348; De Ángel (2014), p. 47. Para el caso chileno, Barros (2020), pp. 384-391. Para este autor, las reglas de responsabilidad por culpa exigen una conexión de ilicitud entre la regla de conducta (cuya infracción funda el juicio de negligencia) y el daño que esa regla persigue prevenir.

${ }^{25}$ PIÑa (2005), pp. 52-54.

${ }^{26}$ Sobre el tema, véase Frisch (1995), p. 173.

${ }^{27}$ Véase Medina (2004), pp. 132-133.

${ }^{28}$ Díez-Picazo (1999), p. 349. Como señala Piña (2005), pp. 55; 57, quien se desempeña en una actividad lucrativa, como un empresario, debe conducirse con el principio normativo de la confianza, en el sentido que, siguiendo a Juan I. Piña: “...no tiene que contar con que su conducta produzca un resultado prohibido debido al comportamiento inadecuado de otro". Hay supuestos, sin embargo, en los que ya no se puede seguir confiando en la actuación del otro. No se trata, como muy bien advierte este autor, de que puedan haberse previsto o no los daños potenciales que puedan surgir para terceros, sino que, por el contrario, de si existe o no una posición de garante en relación con la conducta de un tercero. Véase, FEIJOO (2018), pp. 190-191. 
el resultado. Para corregir estos aspectos Hernán Corral propone adoptar la teoría de la imputación objetiva, con sus adecuaciones al campo civil. Agrega:

"Estimamos de este modo que la previsibilidad del resultado complementado con el análisis del incremento ilícito del riesgo ordinario de la vida constituyen el nexo de causalidad para los efectos de atribuir responsabilidad civil al agente" 29 .

De acuerdo con Enrique Barros, la equivalencia de las condiciones permite determinar (salvo en las omisiones), cuando una causa debe ser considerada necesaria, pero con ello no basta. El principio de la causa necesaria, que establece una condición para que haya responsabilidad, debe ser complementado con un juicio normativo para que se puedan atribuir objetivamente los daños a ese hecho culpable ${ }^{30}$.

\section{LA CREACIÓN DE RIESGOS NO PERMITIDOS, ¿UN PROBLEMA DE CULPA?}

126 Para examinar esta cuestión, debemos tener presente algunas consideraciones previas, que importan una toma de posición en relación con la causalidad y la imputación.

Una primera aproximación para resolver el problema, supone determinar el ámbito al que pertenece el criterio o juicio de la creación de riesgo no permitido. La imputación objetiva puede entenderse como un conjunto de mecanismos normativos destinados a delimitar la órbita de los daños indemnizables. El juicio de imputación se distinguiría del juicio de causalidad que, conforme a reglas científicas, permitiría distinguir o discriminar el círculo de responsables. Este es el papel que tanto Karl Larenz como Fernando Pantaleón, en la recepción que hace para la responsabilidad civil, asignan a la teoría de la imputación objetiva.

En cambio, en el derecho penal, atendida sus propias funciones, la teoría de la imputación objetiva opera en la delimitación del círculo de responsables y, en particular, la idea de Claus Roxin de la creación de riesgos no permitidos permite la desvaloración de la conducta en los delitos

${ }^{29}$ Corral (2004), pp. 191-192. Comparte su opinión, CÁrdenas (2005), p. 547. El análisis de la imputación objetiva se ha extendido también al ámbito de la responsabilidad contractual, articulándose sobre la idea del fin de protección del contrato. Véase, especialmente GonZÁlez (2019), pp. 977-978; DE LA MAZA (2018), p. 637.

${ }^{30}$ Barros (2020), pp. 376-384. 
imprudentes. Esta también es la óptica con la que los autores chilenos han tratado la imputación objetiva. En efecto, en la descripción de Hernán Corral, que adopta los criterios esbozados por Fernando Pantaleón, se piensan como herramientas normativas para delimitar la causalidad fáctica. Enrique Barros, que recurre primordialmente al fin de protección de la norma, también emplea la imputación objetiva en el sentido de criterios normativos para delimitar conductas.

Esta segunda perspectiva es la que adoptaremos a la hora de evaluar si la creación de un riesgo no permitido coincide con el juicio de culpa. Si ello es así, se debe partir de la premisa que la creación de riesgos no permitidos interviene como criterio que permite desvalorar conductas. Ello también es necesario en la responsabilidad civil: decidir, con un criterio normativo, cuáles conductas son injustas y cuáles no. Y, en relación con la causalidad fáctica, la creación de riesgos no permitidos puede intervenir de tres maneras: primero, para complementar el juicio de causalidad fáctico, que opera a través de la supresión mental hipotética; segundo, para corregir los errores a los que conduce la supresión mental hipotética, tratándose de cursos causales hipotéticos o aquellos de causalidad acumulativa y, tercero, para construir el juicio de causalidad, puramente normativa, en el caso de la omisión. A esta última cuestión nos referiremos en particular más adelante.

Una segunda cuestión relevante a la hora de argumentar la coincidencia con la culpa es que, en relación con la imputación objetiva, nos interesa evaluar la manera en la que opera el criterio de creación de riesgos no permitidos y no otros que, pueden o no tener relación con la culpa (o la presuponen), como la previsibilidad o la prohibición de regreso, pues ello importaría referirse a otros problemas que escapan al interés de este trabajo.

Hechas estas advertencias, la cuestión central está en la siguiente pregunta: ¿cómo se determina la creación de riesgo? En otros términos, ¿cuándo estamos en presencia de un riesgo no permitido? Para anotar la coincidencia, aproximémonos a la descripción, en el derecho penal, de la creación de riesgos no permitidos, a propósito del delito imprudente.

Para el delito imprudente, la creación de riesgo no permitido se construye sobre la base de la previsibilidad del riesgo social, como el mecanismo que permite diferenciar cuándo sí y cuándo no, se está en presencia de un riesgo desaprobado. En otras palabras, el denominado criterio de riesgo no permitido, importa un balance de intereses, que permite medir la utilidad social de la actividad versus bienes o intereses protegidos ${ }^{31}$.

${ }^{31}$ Corcoy (2018), pp. 309 y 312. La autora señala: "Lo que ha de valorarse como riesgo permitido no es el ejercicio cuidadoso de la actividad peligrosa, sino el riesgo existente que no resulta abarcado por el deber objetivo de cuidado y que se justifica por la utilidad 
Como indica Yesid Reyes, en principio, el riesgo se caracteriza por la posibilidad de que una acción traiga consigo desventajosas consecuencias. Según el autor, para que un riesgo pueda ser considerado permitido, no basta su utilidad social, sino que a priori no deben existir potenciales víctimas. Fuera de los riesgos permitidos se ingresa a los riesgos desaprobados. En estas se ha excedido el margen de riesgo permitido o las conductas se han realizado sin la observancia de las normas de cuidado previamente establecidas y, aún más, se emplea el criterio del hombre medio, de acuerdo con el círculo de actividades, como mecanismo delimitador ${ }^{32}$.

Por ello, la creación de riesgos no permitidos, antes que resolver una cuestión técnica de imputación, determina una órbita de conductas desaprobadas o desvaloradas ${ }^{33}$. Más allá de algunas discusiones, que dependen de la posición en el campo penal, lo cierto es que, en definitiva, la creación de riesgo no permitido se ha identificado con un problema de injusto $^{34}$. Por ello, no son pocos los autores que consideran que la creación

social de la actividad. Esta concepción del riesgo permitido prueba la utilidad de dicha construcción dogmática, al dotar de contenido propio tanto al deber objetivo de cuidado como al riesgo permitido".

${ }^{32}$ Reyes (2005), pp. 94-98; 107. Como señala Corcoy (2018), pp. 291-293, puede admitirse una clasificación de reglas para determinar cuándo se está frente a un riesgo no permitido, que, por cierto, pueden ser analogadas a la forma de construcción del estándar de comportamiento de la culpa en la responsabilidad civil. Así, se distingue entre reglas de comportamiento social reguladas (lo que se conoce en responsabilidad civil como culpa contra legalidad) o, bien, ámbitos de la vida social que no están regulados, en los que hay que acudir, dice la autora, a los criterios técnicos, autoregulación o costumbre, para definir la adecuación social (lo que correspondería con la determinación del estándar a través de actividades autoreguladas). Véase el extenso tratamiento que sobre esta cuestión realiza Frisch (2004), pp. 101-134, quien va a dividir los tres tipos básicos de conductas que ponen en peligro bienes y que son analizados por el autor: a) limitaciones de conductas de riesgo prejurídico (equivalente a la culpa contra legalidad); b) conducta objeto de limitaciones prejurídicas, como en los casos de reglas técnicas o de convivencia de determinadas actividades; c) ausencia de limitaciones o de reglas prejurídicas, en cuyo caso la desaprobación de comportamientos, como en el caso de la responsabilidad civil, la construye el juez a partir de la vulenración de un estándar de comportamiento medio.

${ }^{33}$ Esta es la idea defendida por FrISCH (2004), p. 82 y ss. Según el autor, la imputación solo debe quedar incorporada la relación causal y la relación entre el riesgo desaprobado, determinado en el injusto típico, y la producción del resultado y considera, por lo mismo, que la relación de causalidad como un subrequisito o parte de la relación de realización, pues, por ejemplo, afirma que la relación causal solo se refiere a los delitos comisivos y no tiene aplicación en los omisivos. Por el contrario, la concreción de riesgos desaprobados, sería un problema de conducta típica, en los que se incorporarían la creación desaprobada de dicho riesgo y el fin de protección de la norma.

${ }^{34}$ Para un resumen de estas posiciones, Anarte (2002), pp. 224-225. Como indica el autor, también hay discusión en cuanto a la adecuación sistemática o metodológica, pues algunos lo ubican en la causalidad, otros piensan que es una causa de justificación y, por tanto, 
de riesgo no permitido coincide con la infracción del deber de cuidado o, más bien, que la primera se agota en la segunda ${ }^{35}$.

¿Qué ocurre en la responsabilidad civil? Comencemos por la idea de culpa, tal como se formula en la dogmática moderna. Siguiendo a H.L.A. Hart, debe distinguirse la inadvertencia de la negligencia, entendida en el lenguaje técnico que empleamos, pues la simple inadvertencia corresponde al juicio ordinario que hacemos de quien desatiende una actividad y provoca un resultado, como una operación psicológica, de quien, por el contrario, se le reprocha por no cumplir con el estándar exigido para el desarrollo de una actividad ${ }^{36}$. Es por lo demás, el concepto de culpa mayoritariamente aceptado en la dogmática chilena y comparada $\mathrm{y}$, a nuestro juicio, es el concepto recogido de la tradición histórica ${ }^{37}$.

En efecto, la culpa no es un reproche que importe un actus non facit reum nisi mens sit rea, sino de un desajuste de las expectativas sociales,

un problema de antijuridicidad, mientras que otros lo ubican, incluso, lo ubican en la culpa. También se le considera como momento determinante del tipo objetivo, ya sea dentro o fuera de la teoría de la imputación objetiva y ello es porque para algunos autores se trataría de un criterio que excluye la autoría, aún antes de la tipicidad. Con todo, mientras para la mayoría de los autores el riesgo permitido sería central en la imputación objetiva, otros autores piensan que se trata de una causa de justificación y ahí debe ser analizada. Por último, hay autores que estiman que se trata de un principio normativo, que actúa funcionalmente en varios momentos, como ocurre de modo similar con la previsibilidad en la responsabilidad civil.

${ }^{35}$ Como indica PIÑa (2005), pp. 52-54, la creación del riesgo permitido queda delimitada por la esfera de la infracción del deber de cuidado. La determinación de los roles sociales, supone que quien no se encuentra en condiciones de alcanzar cierto estándar en la determinación en el desarrollo de una actividad, debe abstenerse de realizar las conductas que implican dicho estándar. Para Álvaro Luna Yerga, los criterios de imputación objetiva restringen el círculo de responsables a aquellos que, dentro del conjunto de causantes del hecho, constituyen una causa próxima y, para llegar a este fin, la imputación objetiva recurre a materiales normativos acerca de la diligencia desplegada por cada uno de dichos causantes. Véase Luna (2004), p. 385.

${ }^{36}$ Hart (2019), pp. 152-154.

${ }^{37}$ Para el concepto de culpa en su fuente histórica, AEdo (2018), pp. 329 y ss. Véase también Honoré (2002), pp. 16-21. Según el autor, de acuerdo con el principio de la culpa, una persona es responsable solo cuando pudo haber controlado la situación en la que se encuentra, pero falla en ello. Solo si una persona pudo haber actuado de otra forma es moralmente responsable y se requiere un reproche para su acción y, en el caso de la negligencia, él es responsable solo cuando podría haber actuado de acuerdo con el estándar requerido. La culpa no se traduce solo en una falta de carácter, sino en la necesidad de remediar dichas faltas para evitar un daño a otro. Según Tony Honoré, Gayo fue el primero en desarrollar una teoría de la culpa, de origen jurídico, no filosófico y cita el conocido caso del muletero, en $D .9,2,8,1$, en el que hace responsable al muletero porque sabía o debía haber conocido su incompetencia antes de decidir manejar las mulas. Entonces, el muletero o conoció su propia incompetencia o fue incapaz de verla -a sus propios ojos él era un hábil conductor-, pudiendo haberla visto. La culpa, así, puede servir para justificar un sistema en el que hay falla en las competencias. 
traducidas en un estándar de comportamiento relativo a otros. Para entender esta cuestión, se debe tener presente que tanto la culpa como la responsabilidad estricta, envuelven un mecanismo de distribución de riesgos sociales. Es falso plantear, por consiguiente, un sistema de culpa versus un sistema de riesgo. La construcción del estándar medio de diligencia en el régimen de culpa determina, de este modo, el ámbito de riesgos que el potencial dañante debe soportar (y, por consiguiente, el ámbito de conductas dañosas que socialmente no serán toleradas) como, asimismo, el ámbito de cuidado que la propia víctima debe asumir. Un sistema de responsabilidad estricta, en cambio, pone todos los riesgos a cargo del potencial dañante, en la medida que la actividad que desarrolla es intrínsecamente riesgosa.

Si la culpa importa que el potencial dañador debe responder con arreglo a un modelo de conducta (y, por consiguiente, no de cualquier grado de culpa), puede sustentarse la hipótesis de que la culpa constituye una herramienta de distribución de riesgos sociales: el estándar de conducta medio que supone el denominado deber de cuidado, plantea una delimitación entre los ámbitos de control del potencial autor del daño y el ámbito en que la víctima debe asumir medidas de cuidado ${ }^{38}$. De esta manera, el estándar de conducta medio que supone la denominada regla de comportamiento, implica una delimitación entre los ámbitos de control del potencial autor del daño y el ámbito en el cual la propia víctima debe asumir medidas de precaución ${ }^{39}$. Y los riesgos de los que se responde, son

${ }^{38}$ Hemos defendido insistentemente la tesis de que la culpa constituye un mecanismo de distribución de riesgos sociales. Para esta cuestión, Aedo (2014), p. 705 y ss.; Aedo (2015a), p. 811 y ss. y AEdo (2018), pp. 342-351. Para el derecho comparado, resulta interesante la aproximación italiana. Véase, por ejemplo, Mario Barcellona, quien afirma que la culpa y el régimen de responsabilidad objetiva son sistemas para determinar el riesgo, el que puede determinarse en concreto o en abstracto. Así, la culpa es un sistema de determinación del riesgo no tolerado. Véase Barcellona (2010), p. 244 y ss. En el mismo sentido, CAfaggi (1996), pp. 162-163; Trimarchi (1961), p. 3 ss.; Trimarchi (1967), pp. 60-63 y, especialmente, Trimarchi (2017), pp. 64-65; 68-70. En el ámbito penal, se trata de una profunda discusión. Para el análisis de la cuestión del control de los riesgos asociados a la actividad del ofensor, véase, por ejemplo, Perin (2017), p. 244 y ss., 254 y MARINUCCI (1991), p. 12.

${ }^{39}$ La tesis de Lilian San Martín coincide con nuestro punto de vista relativo al concepto y función de la culpa. Por un lado, la culpa y la distribución de los riesgos comporta la adopción de medidas de cuidado por la víctima; por otro lado, señalar que en la culpa de la víctima hay un problema de causalidad no excluye la resolución de dichos problemas a través del mecanismo de la culpa. Véase SAn MARTín (2014), p. 35 y ss. En otro trabajo suyo, destaca: "Así las cosas, la diferencia entre culpa exclusiva y concurrente no pasa por la gravedad o calificación jurídica de la conducta de la víctima, sino por la aptitud del demandado para ser considerado responsable del daño y traspasarle su costo, imponiéndole la obligación de indemnizarlo. Esta diferencia se comprueba cuando se considera que 
lo concretos asociados a la actividad. Por ello, el juicio relativo al deber de cuidado, tiene relación con la órbita de actividad del potencial dañante. Atendida la función propuesta para la culpa, tanto un sistema fundado en ella como de responsabilidad estricta, distribuyen y se fundan en el riesgo, pero lo hacen de modo diverso. Así, en el desarrollo de determinada actividad, estaremos frente a una responsabilidad estricta siempre que la totalidad de los riesgos sean asumidos por el autor del daño; por el contrario, la víctima no tiene posibilidad de asumir medidas de cuidado o estas son marginales ${ }^{40}$. Ello explica que la responsabilidad estricta se consagre en actividades en las que el potencial riesgo es inherente a la $\operatorname{actividad}^{41}$.

una misma conducta de la víctima, introducir la mano en la prensa de una fresadora eléctrica, por ejemplo, puede dar lugar a culpa exclusiva o concurrente, dependiendo de si el agente es no considerado responsable. En caso negativo, se habla de 'culpa exclusiva' de la víctima, en caso positivo, de 'culpa concurrente'. La misma conclusión se extrae de todos los demás casos en que la Corte Suprema varía la calificación de culpa exclusiva a concurrente y viceversa o en que existen votos disidentes sobre el punto". Véase SAN Martín (2016), p. 38. Véase también Aedo (2013), p. 505 y ss. Para ver cómo ese contorno de riesgos se distribuye en un escenario de responsabilidad concreto, véase PerIN (2016), con una crítica a la distinción entre imputación objetiva y culpa.

${ }^{40}$ Véase PAPAYANnis (2012), pp. 704-705. Ideas similares ha expresado para el derecho chileno, Pino (2011), p. 23.

${ }^{41}$ Así se consagra, por ejemplo, en los Principios de Derecho Europeo de la Responsabilidad Civil. La Norma fundamental, artículo 1: 101, señala: “(1) La persona a quién puede imputar jurídicamente el daño sufrido está obligada a repararlo. (2) En particular, el daño puede imputarse a la persona: a) cuya conducta culposa lo haya causado; o b) cuya actividad anormalmente peligrosa lo haya causado; o c) cuyo auxiliar lo haya causado en el ejercicio de sus funciones". A su turno, el capítulo $5^{\circ}$ trata la responsabilidad objetiva, y la regula, en el artículo 5:101, para actividades anormalmente peligrosas, en los siguientes términos: "(1) La persona que lleva a cabo una actividad anormalmente peligrosa responde objetivamente por el daño característico del riesgo que tal actividad comporta y que resulta de ella. (2) Una actividad es anormalmente peligrosa si: a) crea un riesgo previsible y significativo de daño incluso aunque se emplee todo el cuidado debido en su ejercicio y b) no es una actividad que sea objeto de uso común. (3) El riesgo de daño puede ser significativo en atención a la gravedad o a la probabilidad del mismo. (4) Este artículo no se aplica a una actividad sujeta específicamente a responsabilidad objetiva por cualquier otra disposición de estos Principios o por cualquier legislación nacional o convención internacional". Como señala MARTín (2005), p. 16: "Debe destacarse que se trata no de una responsabilidad por riesgo sino por un riesgo anormal. Por ello, también debe tenerse en cuenta si esa actividad, que comporta un riesgo muy considerable aun cuando todos los que intervienen en ella actúen de modo diligente, es de práctica común o generalizada (common usage) o no, para excluirla de la cláusula general cuando lo sea. Por supuesto es de práctica generalizada o común aquella actividad que en una determinada comunidad lleva a cabo un número elevado de sus miembros (por ejemplo, la conducción de automóviles). Mas también es de práctica común aquella que lleva a cabo un número limitado de actores (por ejemplo, distribución de gas o de electricidad) pero que es omnipresente en 
La asignación de riesgos a partir de un mecanismo de imputación, cuya función cumple la culpa, para actividades de riesgo ordinario, se conecta muy bien con los fundamentos morales de la responsabilidad civil, tanto para aquellos que fundan una responsabilidad extracontractual en lo que se ha denominado la teoría de la reciprocidad, sustentada por George Fletcher ${ }^{42}$, como aquellos que defienden la culpa, fundándola exclusivamente en la justicia correctiva, como Ernest Weinrib ${ }^{43}$, como aquellos que, como Diego Papayannis, consideran que la justicia distributiva permite la justificación, tanto de un régimen de culpa como estricto (para actividades peligrosas) ${ }^{44}$.

la comunidad y que, por ello, provoca que un gran número de sus miembros se relacione con ella aunque no la practique. Finalmente, también pertenece a esta categoría aquella actividad que, sin ser omnipresente, resulta familiar a los miembros de la comunidad".

${ }^{42}$ Fletcher (1972), p. 537 y ss., afirma que es el riesgo el principio que funda la responsabilidad civil. En la vida social, George Fletcher sostiene que cada miembro de la sociedad tolera o debe tolerar un margen de riesgo derivado de las actuaciones ajenas y a la luz de la propia producción de riesgos frente a los demás. Si quien se embarca de una actividad de riesgo ordinario no adopta los cuidados razonables, y ello se materializa en un perjuicio, entonces ha generado un riesgo no recíproco que debe ser indemnizado. Para las actividades de riesgo anormal o peligrosas, el riesgo recíproco no se aplica y, 132 por tanto, no puede haber balance de riesgos, respondiéndose de los daños conforme a la responsabilidad estricta. Aunque con otra perspectiva muy distinta, enfocando el problema sobre la naturaleza del deber de cuidado, una mirada bilateral al problema de responsabilidad se puede encontrar en la teoría de las normas diádicas de ZIPURSKY(1998), pp. 67-70; ZipURSKY (2013), pp. 233-234, que además se relaciona muy bien con el fin de protección de la norma, como principio causal.

${ }^{43}$ WeINRIB (2013), p. 332, afirma que el mérito de un régimen de culpa se encuentra la descripción del riesgo que debe entenderse como ilícito o desaprobado, del mismo modo que la causalidad la relación de causalidad conecta la culpa del demandado con el daño experimentado por el demandante. Agrega: "Sin embargo, cuando el demandante que sufre el perjuicio es un miembro de la clase de personas que el demandado puso en riesgo, y es la clase de perjuicio o accidente mediante el debido cuidado, entonces la ilicitud de la acción del demandado y el perjuicio del demandante se refieren a la misma clase de riesgo. En estas circunstancias, la secuencia desde la creación de un riesgo irrazonable por el demandado a la materialización de este riesgo en un perjuicio al demandante constituye la misma injusticia para ambas partes". Con todo, si la culpa determina un ámbito de riesgo desaprobado, no parece tan simple distinguir la atribución de la culpa, a menos que la causalidad sea un puro problema fáctico, cuestión que no ocurre en la aproximación moderna de la imputación causal, especialmente en las omisiones. Para ver de qué manera las omisiones fallan en la descripción de la estructura de la voluntad, véase HART (2019), pp. 117-119.

${ }^{44}$ Papayannis (2012), p. 75 indica: "El propósito de la responsabilidad extracontractual tiene que ver con la rectificación de las interacciones injustas y, por lo tanto, con la implementación de la justicia correctiva. Únicamente apelando a este principio es posible hacer inteligible el discurso jurídico de los participantes preservando el sentido que para ellos tienen las doctrinas principales del derecho de daños y el contenido de los conceptos que utilizan para darles forma". Pero, como enfatiza el mismo Papayannis (2013), pp. 
Por tanto, la creación del riesgo no permitido, determinado a partir del deber de cuidado, como la culpa, entendida en el sentido normativo, establecen un radio de conductas que, en definitiva, son desaprobadas socialmente. Y, desde este punto de vista, no cabe duda que la culpa y la creación de riesgo no permitido, superponen el juicio tendiente a desvalorar la conducta y, por cierto, a identificar el causante del daño ${ }^{45}$. Así se ha entendido, tanto en el derecho penal ${ }^{46}$, como en el derecho civil ${ }^{47}$. A esta conclusión tendría que arribarse, incluso, tratándose de cursos causales irregulares, sobre todo en los supuestos de causas hipotéticas, pues el criterio de incremento del riesgo, que se emplea para resolver el problema del comportamiento alternativo conforme a derecho, también queda integrado $\mathrm{y}$, por consiguiente, agotado, con la infracción del deber de cuidado ${ }^{48}$.

400-401, para que opere la justicia correctiva, es necesario que opere antes la justicia distributiva. Y, según el autor, lo que distribuyen son derechos y deberes de indemnidad. En dicha distribución, caben las reglas de responsabilidad por culpa y las de responsabilidad estricta: "Dado que cada regla tiene efectos distributivos distintos, ellas establecen distintos contenidos para los derechos de indemnidad de cada una de las partes. La regla de responsabilidad por culpa implica un derecho a no ser dañado por conductas negligentes o dolosas a otras personas, y un correlativo deber de no dañar de ese mismo modo; la regla de responsabilidad objetiva, por su parte, supone un derecho a no ser dañado por conductas inusualmente peligrosas". Esta idea, ahora atendida desde la justicia distributiva, que la incorpora, puede conectarse con el argumento de que tanto la culpa, como la responsabilidad estricta, operan como mecanismo de distribución de riesgos sociales.

${ }^{45}$ Para las conflucencias entre causalidad y culpa en la filosofía del Derecho, materia en la que no podemos detenernos, véase AEDo (2017b), pp. 512-513.

${ }^{46}$ Véase el extenso tratamiento que sobre esta cuestión realiza Frisch (2004), p. 101 ss. Sobre este tema específico véase también el opúsculo Frisch y Robles Planas (2006) y Frisch (1995), p. 30. Según Wolfgang Frisch, en la imputación objetiva hay dos niveles de imputación: en el primero, se trataría de desaprobar conductas, lo que escondería, para el autor, una valoración de la conducta de acuerdo con la previsibilidad. Véase también, AnARTE (2002), pp. 339-340 y PelÁEz (2018), p. 315. La coincidencia es anotada, a modo de crítica, por un sector importante de la dogmática penal. Véase MARInUCCI (1991) pp. 7-8. Como afirma: “... ma per mostrare, ancora una volta, che il nome di imputazione 'oggettiva' dell'evento sta solo a denotare l'imputazione per 'colpa' dell'evento, 'giuridicamente rilevante' e infatti la creazione o l'aumento del rischio se e in quanto contrasta con il 'dovere di diligenza', individuato alla stregua dei collaudati criteri della moderna teoria della colpa". El reproche de Giorgo Marinucci, en el sentido de determinar el riesgo con la infracción del deber de cuidado, ya se encuentra en la formulación de ENGISCH (2008), p. 60 ss. y ha sido defendido por importantes autores como, por ejemplo, GimBERnAT (2018a), p. 92; JaKobs (1997), pp. 245-246; Kaufmann (1976), p. 480 y ss.

${ }^{47}$ Así lo hizo ver expresamente De Ángel (2014), p. 250, al señalar que en el ámbito civil resulta imposible distinguir el riesgo permitido del respectivo análisis de culpa que debe hacerse. Véase también el interesante trabajo de SALVADOR, Garoupa y Gómez (2005), p. 3; y, Salvador, Ramos, Luna y Ruiz (2004), p. 4501.

${ }^{48}$ Este es un problema complejo en el que no podemos detenernos en detalle. Para su tratamiento en el derecho penal, véase Gimbernat (2018b), pp. 13-63. Como explica el 
Hay un último aspecto en el que termina por advertirse la integración de ambos elementos, es decir, la creación de riesgo no permitido, por un lado, y de la culpa, por otro. Si, como hemos analizado, en ambos casos se parte de la premisa de la libertad de los sujetos y, se adopta un criterio para deslindar los riesgos sociales que, del desarrollo de una actividad resultan desaprobados, necesariamente dicha determinación debe ser $e x$ post ${ }^{49}$, con arreglo a los riesgos concretos de la actividad. Así se ha resuelto en el ámbito penal ${ }^{50}, \mathrm{y}$, para la responsabilidad civil, es la fórmula

autor, hay dos grandes teorías para resolver el problema de los cursos causales hipotéticos. Con la denominada teoría de la evitabilidad, el resultado no se puede imputar si el mismo resultado se hubiera conseguido con el comportamiento conforme a derecho. La teoría varía según si se exige certeza o mera probabilidad para la determinación del curso causal alternativo, pero en todo caso, la tesis se hace operar desde el principio in dubio pro-reo y mientras más se recurre a la probabilidad, dicho principio se hace pesar todavía más. Con la idea del incremento del riesgo, introducida por Claus Roxin, se persigue determinar si la infracción del deber de cuidado representa un aumento significativo para la víctima, comparada con la situación anterior a dicha infracción. Si la respuesta es positiva, procedería la condena. Aunque ambas fórmulas tienen patrocinadores y detractores, lo que importa destacar en este lugar, es la imposibilidad de aplicarlas a la responsabilidad 134 civil, desde la lectura de la reparación y no de la pena. Uno de los casos paradigmáticos de curso hipotético nos ayudará a reflejar lo dicho. Si un médico opera a un paciente con grave negligencia o con infracción manifiesta a la lex artis, y luego se comprueba que, a pesar de haber operado apegado a la lex artis, el paciente hubiese muerto de todos modos. Para el derecho penal, parecería justificada la discusión relativa al comportamiento lícito alternativo, en orden a que el fundamento del régimen es la pena que se asigna a un sujeto. Pero en la medida que la responsabilidad civil persigue la reparación, parece que basta la infracción del deber de cuidado para afirmar la responsabilidad, configurando ésta el incremento del riesgo para la víctima.

${ }^{49}$ Se ha postulado que la distinción entre el criterio de imputación objetiva y el deber de cuidado, estaría en que los riesgos permitidos serían determinados ex ante, conforme a la determinación de riesgos generales, por un lado y, el deber de cuidado, que determinaría la desaprobación de conductas ex post. La contraposición es, con todo, aparente. Como explica Corcoy (2018), pp. 311-312, ex ante una actividad que representa una utilidad social puede evitar los riesgos o peligros asumiendo determinadas medidas de cuidado, de manera que, en sus palabras: "Lo que ha de valorarse como riesgo permitido no es el ejercicio cuidadoso de la actividad peligrosa, sino el riesgo existente que no resulta abarcado por el deber objetivo de cuidado y que justifica la utilidad social de la actividad". Ello le conduce a decir que riesgo permitido y deber de cuidado no se superponen, sino que se contraponen. Ergo, si se trata de riesgo no permitido, debería concluirse la identificación, especialmente tratándose de la teoría de la evitabilidad.

${ }^{50}$ Así lo explica Frisch (2004), pp. 88-89, quien indica que con arreglo a un juicio $e x$ ante, no pueden desaprobarse todos los riesgos que entrañen peligro para el o los bienes jurídicos. Por eso, señala que tiene que tratarse de un peligro concreto, aun cuando el autor prefiere denominarlo concreción del riesgo. En el mismo sentido, CASTALDO (2008), p. 181, también considera que se trata de una evaluación de riesgos concretos, ex post. 
que hemos defendido, asignando a la culpa la función de distribución de riesgos sociales concretos asociados a la actividad ${ }^{51}$.

Resta ver, por último, si la coincidencia entre creación de riesgo no permitido y la culpa, tiene consecuencias en el terreno de la causalidad y cuál sería la extensión de dichas consecuencias.

A nuestro juicio, la identificación de la culpa con la creación de riesgo no permitido solo puede evaluarse en el plano o ámbito del desvalor de conducta y no en el ámbito del desvalor de resultado. En otras palabras, tanto la creación de riesgo no permitido como la culpa, integrarían el juicio de causalidad normativa en su primer aspecto, es decir, en cuanto identifica el o los responsables y no en cuanto delimita la órbita de los daños indemnizables. Este segundo problema, de la delimitación de los daños reparables, es ajeno al interés de este trabajo.

Siendo este el ámbito de la correspondencia entre creación de riesgo no permitido y culpa, no puede evaluarse dicha equivalencia del mismo modo, tratándose de las acciones y de las omisiones. En el caso de la acción, para la determinación del círculo de responsables, no cabe duda que el test de la equivalencia de las condiciones y la supresión mental hipotética permite afirmar la causalidad, a menos que nos encontremos en presencia de problemas de causalidad hipotética, concurrente o, bien, cuando los cursos causales no son previsibles acorde con la experiencia científica previa ${ }^{52}$. En los casos de falla de la supresión mental, se podrá recurrir a correctivos que la doctrina ha ofrecido para la determinación de la causalidad material. La culpa, por su parte, en el régimen de los

${ }^{51}$ Para esta cuestión, AEdo (2018), pp. 348-351, con la jurisprudencia citada. Que la actividad de riesgo que se determina no puedan ser los riesgos ex ante de una actividad, lo explica WRIGHT (2008), pp. 1296; 1312-1313. "Risks are merely abstract ex ante statistics that report the frequency of occurrence of some harm given a specified set of conditions. Unlike the actual occurrence of such harm, risks per se do not constitute an actual setback to another's equal external freedom through an invasion of the other's rights in his person or property, as is required for an interactive justice wrong. Treating the risk exposure as the legal injury, but only when the risked harm actually occurs and only in the problematic causation situations, is an ad hoc solution that, among other problems, fails to explain why recovery is contingent on the actual occurrence of the risked harm and why the damages are based on the ex post actual harm rather than the ex ante expected harm".

${ }^{52}$ Para este problema, véase Roxin (1997), pp. 350-351. Para los déficit de la teoría, véase, por todos, Trimarchi (2017), p. 452. La doctrina ha venido estimando que, frente a casos en los que no puede ser determinada la causalidad absolutamente, esta debe ser establecida por la vía de la estimación de la probabilidad de que el daño se daba a un hecho por el cual el demandado sería responsable. Como afirma BARros (2020), pp. 379-380, los casos de causalidad probable se construyen sobre la base del incremento de riesgo o, como diría BARCELlONA (2010), p. 282, constituyen un sistema sobre la base del riesgo que se ha creado (y que, por consiguiente, hipotéticamente, como todo juicio causal, pudo haberse evitado). 
cuasidelitos, operará como principal criterio normativo de decisión de cuestiones causales. Pero ello no obsta para que las cuestiones de imputación (sea en la determinación de los responsables o en la delimitación de los daños), sean auxiliadas por otras herramientas normativas que propone la imputación objetiva en sede civil, como la prohibición de regreso o el fin de protección de norma. Aun así, en ambos casos se pueden encontrar claras conexiones con la culpa ${ }^{53}$.

En las omisiones ${ }^{54}$, la cuestión se resuelve según la aproximación que se defienda sobre la naturaleza de la causalidad ${ }^{55}$. En efecto, si la causalidad es una relación del pensamiento o una categoría del pensamiento, que importa la relación de vinculaciones y no una categoría ontológica, la causalidad puede afirmarse en las omisiones, con la aplicación de la teoría de la equivalencia y su juicio hipotético, a la inversa ${ }^{56}$. Si, en cambio, la causalidad es una categoría ontológica, la omisión no puede vincularse causalmente con el daño, pues la causalidad es una categoría del ser, y no una relación del pensamiento ${ }^{57}$.

En esta materia, por consiguiente, debe adoptarse una postura. Si la causalidad es una cuestión ontológica, prejurídica, idea que suscribimos,

${ }^{53}$ Véase De ÁNGel (2014), pp. 227-236.

$136 \quad{ }^{54}$ En el establecimiento de la negligencia no puede silenciarse el análisis de la posición de garante que detenta el demandado dentro de la comunidad de riesgos en la cual todos estamos insertos. En doctrina civilista, hay un cierto debate entre la tesis de los profesores Arturo Alessandri y Hernán Corral, a propósito de la conducta, pero que se proyecta en la idea de construcción del estándar en la culpa. Según el primero (aunque abordado a propósito de lo que denomina la abstención en la acción), el deber de garante se puede reconducir a la regla general de responsabilidad, establecida en el citado art. 2314. Hernán Corral, en cambio, piensa que el deber de garante solo excepcionalmente no debiera ser formal, porque de otro modo, se correría el riesgo de afectar la libertad de los sujetos. Alessandri (2005), n. ${ }^{\circ} 134$, p. 200. Corral (2004), pp. 112-113. Para el tratamiento penal, véase Welzel (2002), p. 293 y ss.; Gimbernat (2018a), pp. 1-8 y para la construcción del deber de garante, 123 y ss. Para la distinción de diversos tipos de omisión, Frisch (2004), pp. 264-283. Para un enfoque en el derecho penal, en términos de vincular la creación de riesgos no permitidos y el deber de garante con la construcción del estándar de diligencia, véase JaKobs (1997), pp. 124-128.

${ }^{55}$ Como afirma Anarte (2002), p. 379 y ss., en el derecho penal, como en otras ramas relacionadas, desde luego, la responsabilidad civil, se afirma el principio de la causalidad, pero sin determinarse qué debe entenderse por causalidad, pues esta respuesta no ha sido dada por ninguna rama científica, existiendo vivas discusiones, sea en cuanto a las características cualitativas o cuantitativas de la causalidad (necesidad, regularidad, probabilidad), sea en cuanto a la naturaleza de la relación (real, psicológica, ideal) y, consecuentemente, el modo de acceder a ella (observación, observación/deducción, mera elucubración mental).

${ }^{56}$ Véase, por todos, Gimbernat (2018a), pp. 373-376.

${ }^{57}$ Para esta cuestión Gimbernat (2018a), p. 47 y ss.; Anarte (2002), p. 403; CorcoY (2018), p. 394. 
la conexión causal deberá ser normativa. De ahí que si, el juicio de imputación normativo en la omisión es la creación de riesgo no permitido, puede afirmarse que en el caso de conductas omisivas, la causalidad queda determinada por la culpa ${ }^{58}$. En consecuencia, en los casos de omisión pura o, más concretamente de comisión por omisión, así como en los casos de causalidad mediata, la causalidad se construye a partir de un deber de garante, equivale a resolver normativamente la causalidad a través de la culpa ${ }^{59}$.

Si se aceptan estos presupuestos, pueden ensayarse algunas conclusiones que se ofrecen en este trabajo.

\section{Conclusiones}

La configuración del sistema variará dependiendo de la concurrencia de antijuridicidad formal y del tipo de conducta desplegada ${ }^{60}$. A modo preliminar, se pueden señalar las siguientes conclusiones:

- El núcleo de la imputabilidad radica en el entendimiento y la voluntad de la acción humana, es decir, se construye sobre el presupuesto de la actio voluntaria en relación con un mundo determinado, que supone, a su vez, igualdad y libertad. La idea de imputación recae sobre la intervención que dicha libertad hace sobre los sucesos naturales.

- En su primer estadio, lo que se denomina imputación, no es sino la desaprobación de comportamientos sociales que, en el balance de intereses en juego, delimitan una órbita de riesgos de los que se responde, lo que posibilita la convivencia social. Este balance de intereses importa que la creación de riesgos no permitidos,

${ }^{58}$ Véase, en este sentido, JAKOBS (1997), pp. 26-27; CASTALdo (2008), p. 54, quien afirma: "En lo que concierne a la estructura de la omisión, se niega en general la funcionalidad de una ley de causalidad en clave naturalista (ex nihilo nihil fit) debiéndose comprobar mediante una verificación hipotética el efecto de la acción omitida sobre el resultado que la norma incriminadora deseaba impedir". En efecto, en el campo penal, con todo, se ha ofrecido, para el caso de las omisiones, la determinación de la causalidad a partir de un juicio normativo, hipotético, traducido en la conducta necesaria para que el autor hubiese evitado el hecho o se minimicen las chances para el resultado dañoso. En estos casos, el juicio, normativo, se reconstruye sobre la base de una prognosis de probabilidad causal. Véase PERIn (2018), pp. 8-9; 19-26. Para la responsabilidad civil, véase la aproximación de CAPecchi (2012), pp. 136 ss., 262. Para el derecho chileno, véase Barros (2020), p. 380.

${ }^{59}$ Para ver de qué manera las omisiones fallan en la descripción de la estructura de la voluntad, véase HarT (2019), pp. 117-119.

${ }^{60}$ Una propuesta de sistema para el derecho chileno, con las que adoptamos conclusiones similares, puede verse en AEDo (2017b), pp. 514-515. 
incide en la determinación del círculo de responsables y no en la delimitación de los daños indemnizables.

- Dicho balance de intereses se hace ex post, sobre la base de los riesgos concretos que una actividad representaría en la lesión de intereses ajenos. Es decir que, aunque el juicio de determinación de riesgos es objetivo, se concreta en las circunstancias de tiempo y lugar.

- Tanto la propuesta de creación de riesgos no permitidos como el tradicional criterio de la culpa, que envuelve la infracción de un deber de cuidado, superponen ese papel de delimitación de comportamientos sociales desaprobados, en actividades de riesgo social ordinario y, por tanto, de utilidad social. Esta cuestión ha sido defendida por eminentes penalistas, como Wolgang Frisch, Armin Kaufmann, Enrique Gimbernat o Giorgo Marinucci. Y es la misma fórmula que proponemos en este trabajo.

- A favor del juicio de culpa, existe una larga tradición históricodogmática en el derecho privado. El juicio de imputación que, aunque con raíces hegelianas se puede rastrear hasta Samuel $\mathrm{Pu}-$ fendorf, no constituye sino, al menos en este ámbito concreto analizado, un juicio de culpa ${ }^{61}$. También por razones históricas, decide

${ }^{61}$ Como afirma SAn Martín (2018), pp. 50-51, no puede negarse una intrínseca conexión entre el juicio de causalidad y el juicio de culpa, que tiene innegable raíz histórica, en la medida que, en el sistema de culpa, interesa rescatar solo el comportamiento culpable. Para el derecho comparado, léase la autorizada voz de Honoré (2013), p. 1079: "En los casos de responsabilidad por culpa, la conexión causal (Kausalzusammenhang en la terminología alemana) no puede ser separada de la conexión ilegal (o ilícita) (Rechtswidrigkeitszusammenhang); la separación de estos conceptos, planteada por algunos autores alemanes, es una fuente de error. El punto es dilucidar si una determinada conducta culposa (o una conducta creadora de riesgo que da lugar a una acción responsabilidad estricta) causó un determinado daño". Agrega: "En responsabilidad extracontractual el punto no consiste en plantearse la pregunta abierta 'cंcuál fue la causa de este daño?', sino '¿fue causado el daño por el hecho que el demandado se comportara de manera ilícita o creando un riesgo indebido?'. La primera pregunta requiere de una explicación de cómo se produjo el daño, mientras que la segunda pregunta requiere de un análisis de la responsabilidad del demandado por la conducta descrita en categorías establecidas por la ley". De todos modos, se trata de una función histórica, como hemos probado en otro lugar. Véase AEdo (2015b), p. 61 y ss.

Lo cierto es que este argumento entronca con la tradición chilena. La doctrina chilena tradicional, encabezada por AlesSANDRI (2005), pp. 174; 176, al analizar la relación de causalidad, estima que esta se configura cuando puede conectarse la culpa o el dolo con el resultado dañoso: "Para que el hecho o la omisión de una persona capas de delito o cuasidelito civil le imponga responsabilidad delictual o cuasidelictual civil, no basta que ese hecho u omisión haya sido ejecutado con dolo o culpa, ni que cause daño. Es menester que entre el dolo o la culpa, por una parte, y el daño, por la otra, haya una relación de causalidad, es decir, que éste sea consecuencia o efecto de ese dolo o culpa [...]. Un delito o cuasidelito obliga, por tanto, a la indemnización cuando conduce a un daño, cuando 
el abandono de la nomenclatura culpa, para reflexionar sobre la base de imputación, dado el interés de la escuela del iusnaturalismo racionalista por el abandono del derecho romano ${ }^{62}$.

- Por tanto, en la comisión, así como en la omisión, la desaprobación de conductas se hace en razón de la infracción de un deber de cuidado. No puede deslindarse la cuestión de la culpa y de la causalidad, en lo relativo a la creación de riesgos desaprobados. Esta relación es mucho más intensa en la omisión, en la medida que la causalidad sea comprendida como un problema ontológico, prejurídico. Al haber ausencia de causalidad en la omisión, la conexión normativa y, por consiguiente, tanto la desaprobación del comportamiento y su vinculación con el resultado, se efectúa también con la culpa. En este punto, la culpa goza de una larga tradición histórica, que se remonta a la lex Aquilia ${ }^{63}$.

- Finalmente, que la culpa constituya un criterio normativo de determinación de la causalidad, al superponerse con la creación de riesgos no permitidos, no significa que pueda constituir el único juicio. Es posible que al juicio de culpa, en tanto criterio normativo de determinación del juicio causal fáctico, pueda ser complementado con otros criterios normativos, como el fin de protección de la norma ${ }^{64}$.

\section{Bibliografía CITADA}

Aedo Barrena, Cristian (2006). Responsabilidad extracontractual. Santiago: Librotecnia.

Aedo Barrena, Cristian (2013). "El tratamiento dogmático de la culpa de la víctima en la responsabilidad civil: un enfoque desde la imputación objetiva”,

éste es su resultado, cuando el daño se induce de él, cuando el daño puede atribuirse a la malicia o negligencia de su autor". Y, como enseña BARROS (2020), p. 380: "Ante todo, es injusto que quien haya creado un riesgo sustancial, sin incurrir en el cuidado debido, jamás sea responsable, a pesar de que la materialización de ese riesgo es un cierto porcentaje de víctimas resulte comprobable; si así fuere, la balanza se inclina sin justificación en perjuicio de las víctimas. También desde el punto de vista preventivo se justifica aceptar la causalidad basada en la probabilidad: sólo así quien provoca el riesgo tiene incentivos proporcionales para evitarlo. Todo indica, en consecuencia, que, a falta de norma expresa, la probabilidad significativa de que el daño se deba a la negligencia del demandado puede dar lugar a la responsabilidad".

${ }^{62}$ Para la justificación de esta afirmación, véase nuestro trabajo AEdo (2018), pp. 62-68.

${ }^{63}$ Véase Aedo (2015a) p. 66 y ss.; Aedo (2018) p. 113 y ss.

${ }^{64}$ Sobre este punto, véase, en el mismo sentido, y con los ejemplos que muestra SAN Martín (2018) p. 52. 
en Carmen Domínguez Hidalgo y otros (coords.). Estudios de Derecho Civil VIII. Jornadas Nacionales de Derecho Civil. Santa Cruz, 2012. Santiago: Legal Publishing.

Aedo Barrena, Cristian (2014). "El concepto normativo de culpa como criterio de distribución de riesgos. Un análisis jurisprudencial". Revista Chilena de Derecho, vol. 41, n. ${ }^{\circ} 2$.

Aedo Barrena, Cristian (2015a). "La culpa como criterio de distribución de riesgos sociales ¿Hay en la culpa una infracción a un deber jurídico?", en Álvaro Vidal Olivares, Gonzalo Severin Fuster y Claudia Mejías Alonso (coords.). Estudios de Derecho Civil X. Santiago: Thomson Reuters.

Aedo Barrena, Cristian (2015b). "La cuestión causal en la lex Aquilia y su solución mediante el mecanismo de la culpa". Revista de Estudios HistóricoJurídicos, volumen XXXVII.

Aedo Barrena, Cristian (2017a). "La causalidad como imputación objetiva", en Alejandro Guzmán Brito (editor científico), Rodrigo Momberg Uribe, Alexis Mondaca Miranda, Daniela Jarufe Contreras y Cristian Aedo (coords.). Aportaciones adicionales a nuevos horizontes en el Derecho Privado. Valparaíso: Ediciones Universitarias de Valparaíso.

Aedo Barrena, Cristian (2017b). "La creación de riesgos no permitidos en la imputación objetiva, ¿un problema de culpa? Hacia un sistema funcional", en Hernán Corral Talciani y Pablo Manterola Domínguez (eds.). Estudios de derecho civil XII. Santiago: Thomson Reuters.

Aedo Barrena, Cristian (2018). Culpa aquiliana: una conjunción de aspectos históricos y dogmáticos. Santiago: Thomson Reuters.

Aedo Barrena, Cristian (2019). "La culpa como fundamento de la responsabilidad civil extracontractual", en Esteban Pereira Fredes (ed.). Fundamentos filosóficos del Derecho Civil chileno. Santiago: Rubicón Editores.

Alessandri Rodríguez, Arturo (2005). De la responsabilidad extracontractual en el derecho civil chileno. Reimpresión de la $1^{\text {a }}$ ed. Santiago: Editorial Jurídica de Chile.

AlPA, Guido y Mario Bessone (1976). La responsabilità civile: illecito per colpa, rischio d'impresa, assicurazione. Milano: Giuffrè.

Anarte Borrallo, Enrique (2002). Causalidad e imputación objetiva. Estructura, relaciones, perspectivas. Huelva: Publicaciones Universidad de Huelva.

Barcellona, Mario (2010). Trattato della Responsabilità Civile. Torino: UTET.

Bacigalupo, Enrique (2004). Derecho penal. Parte general. Lima: Ara Editores.

Barcia Lehmann, Rodrigo (2010). Lecciones de derecho civil chileno. Reimpresión de la $1^{\text {a }}$ edición. Santiago: Editorial Jurídica de Chile. Tomo II: De las fuentes de las obligaciones.

Barros Bourie, Enrique (2020). Tratado de responsabilidad extracontractual. $2^{\text {a }}$ edición. Santiago: Editorial Jurídica de Chile.

Belvedere, Andrea (2006). “Causalitá giuridica?”. Rivista di Diritto Civile, vol. LII. 
Cafaggi, Fabrizio (1996). Profili di relazionalità della colpa. Contributo ad una teoría della responsabilità extracontrattuale. Padova: CEDAM.

CAPECCHI, Marco (2012). Il nesso di causalità. Dalla condicio sine qua non alla responsabilità proporzionale. $3^{\mathrm{a}}$ edición. Padova: Cedam.

Cárdenas Villarreal, Hugo (2005). "Reflexiones sobre la teoría de la imputación objetiva y su aplicabilidad en el ámbito civil", en Juan Andrés VARAS Braun y Susan Turner Saelzer (coords.). Estudios de derecho civil I. Jornadas nacionales de derecho civil. Valdivia. Santiago: LexisNexis.

Castaldo, Andrea (2008). La imputación objetiva en el delito culposo de resultado. (trad.) Antonio Bonanno. Buenos Aires: B de F.

Castronovo, Carlo (2018). Responsabilitá Civile. Milano: Giuffré.

Cerezo Mir, José (2008). Derecho penal. Parte general. Buenos Aires: B de F.

Corcoy Bidasolo, Mirentxu (1994). "Imputación objetiva en el delito imprudente", en AA.VV. Causalidad e imputación objetiva. Madrid: Consejo del Poder Judicial.

Corcoy Bidasolo, Mirentxu (2018). El delito imprudente. Criterios de imputación del resultado. $2^{\text {a }}$ edición. Buenos Aires-Montevideo: B de F.

Corral TAlciani, Hernán (2004). Lecciones de responsabilidad civil extracontractual. Reimpresión de la $1^{\mathrm{a}}$ edición. Santiago: Editorial Jurídica de Chile.

De Ángel YÁGüEz, Ricardo (1993). Tratado de responsabilidad civil. Madrid: Civitas.

De Ángel YÁGüEz, Ricardo (2014). Causalidad en la responsabilidad extracontractual: sobre el arbitrio judicial, la imputación objetiva y otros extremos. Madrid: Thomson Reuters.

De la Cuesta Aguado, Paz (1996). Tipicidad e imputación objetiva. Reimpresión de la $1^{\mathrm{a}}$ edición. Mendoza: Ediciones Jurídicas de Cuyo.

De la Maza Gazmuri, Iñigo (2018). "Previsibilidad y causalidad”, en Claudia Bahamondes Oyarzún, Leonor Etcheberry Court y Carlos Pizarro Wilson (eds.). Estudios de derecho civil XIII. Santiago: Thomson Reuters.

Díez-Picazo, Luis (1999). Derecho de daños. Madrid: Civitas.

DíEz-PicAzo, Luis (2007). Fundamentos de derecho civil patrimonial. Madrid: Thomson Reuters-Civitas.

Díez Schwerter, José Luis (1998). El daño extracontractual. jurisprudencia y doctrina. Santiago: Editorial Jurídica de Chile.

Drapkin, Abraham (1943). Relación de causalidady delito. Santiago: Editorial Cruz del Sur.

EngISCH, Karl (2008). La causalidad como elemento de los tipos penales. (trad.) Marcelo Sancinetti. Buenos Aires: Hammurabi.

Feijoo SÁnchez, Bernardo (2018). Imputación objetiva en el derecho penal. Nuevos alcances. Santiago: Olejkik-Ibáñez.

Fletcher, George (1972). "Fairness and Utility in Tort Theory". Harvard Law Review, volume 85. 
FRIScH, Wolfgang (1995). Tipo penal e imputación objetiva. Madrid: Marcial Pons.

FRISCH, Wolfgang (2004). Comportamiento típico e imputación del resultado. (trad.) de la edición alemana de 1988 por Joaquín Cuello Contreras y José Luis Serrano González de Murillo. Madrid: Marcial Pons.

Frisch, Wolfgang (2014). La imputación objetiva del resultado. Desarrollo, fundamentos y cuestiones abiertas. Barcelona: Atelier Libros.

Frisch, Wolfang y Ricardo Robles Planas (2006). Desvalorar e imputar. Sobre la imputación objetiva en derecho penal. $2^{\mathrm{a}}$ edición. Montevideo-Buenos Aires: Editorial B de F.

Gimbernat Ordeig, Enrique (2018a). Estudios sobre el delito de omisión. MontevideoBuenos Aires: B de F.

Gimbernat Ordeig, Enrique (2018b). El comportamiento alternativo conforme a Derecho. De la causalidad a la imputación objetiva. Montevideo-Buenos Aires: B de F.

González Cazorla, Fabián (2019). "Imputación objetiva de los daños por incumplimiento contractual". Revista Chilena de Derecho, volumen 46, n. ${ }^{\circ} 3$.

Hart, H.L.A. \& Tony Honoré (1990). Causation in the Law. Oxford: Clarendon Press.

Hart, H.L.A. (2019). Castigo y responsabilidad. Ensayos de filosofía del derecho. (trad.) Jacobo Barja de Quiroga y León García-Comendador Alonso. Madrid: Marcial Pons.

HrusckA, Joachim (2005). "La imputación ordinaria y extraordinaria en Pufendorf. Sobre la historia y el significado de la diferencia entre actio libera in se y actio libera in sua causa", en Nuria Pastor Muñoz y Pablo Sánchez Ostiz (coords.). Imputación y derecho penal. Estudios sobre la teoría de la imputación. Madrid: Thomson-Aranzadi.

Honoré, Anthony (2002). Responsibility and fault. Oxford, Portland: Hart Publishing.

Honoré, Anthony (2013). "Condiciones necesarias y suficientes en la responsabilidad extracontractual”. (trad.) Alberto Pino y Arturo Ibáñez. Revista Chilena de Derecho, volumen 40, n. ${ }^{\circ} 3$.

JaKoвs, Günter (1997). La imputación objetiva en el derecho penal. (trad.) Rubén Villela. Reimpresión de la $1^{\mathrm{a}}$ edición. Buenos Aires: Editorial Ad-Hoc.

Jescheck y Weigend, Thomas (2002). Tratado de derecho penal. Parte general. $5^{\mathrm{a}}$ edición. (trad.) Miguel Olmedo Cardenete. Granada: Comares.

Kaufmann, Armin (1976). "El delito culposo". Revista Nuevo Pensamiento Penal, n. ${ }^{\circ} 5$.

Larenz, Karl (1958). Derecho de obligaciones. Madrid: Editorial Revista de Derecho Privado.

LóPEz, Cristian (2018). “¿Qué puede decirnos la relatividad general respecto de la flecha del tiempo?”. Revista Ins. Fil. Campinas, volumen 41, n. ${ }^{\circ} 3$.

Luna Yerga, Álvaro (2004). La prueba de la responsabilidad civil médico-sanitaria. Madrid: Thomson-Civitas. 
Malaurie, Philippe; Laurent Aynés et Philippe Stoffel-Munck (2015). Droit des Obligations. $8^{\text {ème }}$ édition. Paris: LGDJ.

MARINUCCI, Giorgo (1991). "No c'è dolo senza colpa". Morte della «imputazione oggettiva dell'evento» e trasfigurazione nella colpavolezza". Rivista italiana di Diritto e procedura penale, $\mathrm{N}^{\circ} 11-2$.

Martín Casals, Miquel (2005). "Una primera aproximación a los 'Principios de Derecho Europeo de la Responsabilidad Civil'”. Indret, n. ${ }^{\circ} 2$.

Mazeaud, Henri, Leon Mazeaud y André Tunc (1977). Tratado teórico y práctico de la responsabilidad civil delictual y contractual.(trad.) de la $5^{\mathrm{a}}$ edición francesa por Luis Alcalá-Zamora y Castillo. Buenos Aires: Ediciones Jurídicas Europa-América.

Medina Alcoz, María (2004). "El debate histórico de la subjetividad versus la objetividad de la responsabilidad civil en Francia y su proyección en España. El equilibrio de su convivencia actual en el Derecho español", en José Manuel González Porras y Fernando Pedro Méndez González (coords.). Libro homenaje al profesor Manuel Albaladejo García. Murcia: Colegio de Registradores de la Propiedad y Mercantes de España, Universidad de Murcia, tomo I.

Owen, David (1997). "Philosophical Foundations of fault in Tor Law", in David Owen (ed.). Foundations of Tort Law. Oxford: Clarendon.

Pantaleón Prieto, Fernando (1991). "Causalidad e imputación objetiva: Criterios de imputación”, en AA.VV. Centenario del Código Civil. Madrid: Asociación de profesores de Derecho Civil, tomo II.

Papayannis, Diego (2012). "Derechos y deberes de indemnidad". Doxa. Cuadernos de Filosofía del Derecho, n. 35.

Papayannis, Diego (2013). "Derechos y deberes de indemnidad", en Carlos Bernal Pulido y Jorge Fabra Zamora (eds.). La filosofía de la responsabilidad civil. Bogotá: Universidad del Externado.

Peláez Mejía, José María (2018). "La necesidad del análisis causal frente a la teoría de la imputación objetiva en el derecho penal". Revista de Derecho (Valdivia), volumen XXXI, n. ${ }^{\circ} 2$.

Perin, Andrea (2016). "La contribución de la víctima y la imputación objetiva del resultado en la teoría del delito imprudente". Revista Electrónica de Ciencia Penal y Criminología, 18-19.

Perin, Andrea (2017). "La condotta lesiva colposa. Una prospettiva ricostruttiva". Politica Criminal, volumen 12, n. ${ }^{\circ} 23$.

Perin, Andrea (2018). "Limputazione oggettiva dell'evento per omissione impropria. Argimenti a favore della 'disminuzione di chances'". Archivio Penale, $\mathrm{N}^{\circ} 2$.

Pino Emhart, Alberto (2011). "Justicia distributiva, responsabilidad civil y terremotos". Derecho y Justicia, n. ${ }^{\circ} 123$.

Piña Rochefort, Juan Ignacio (2005). "La imputación de responsabilidad penal en los órganos de la empresa y sus efectos en sede civil", en Jorge BARAONA GonzÁlez y Pedro Zelaya Etchegaray (eds.). La responsabilidad por accidentes del trabajo. Santiago: Cuadernos de Extensión Jurídica, n. ${ }^{\circ} 10$. 
Prevot, Juan Manuel (2010). "El problema de la relación de causalidad en el Derecho de la responsabilidad civil". Revista Chilena de Derecho Privado, n. ${ }^{\circ} 15$.

Quézel-Ambrunaz, Christophe (2010). Essai sur la causalité en droit de la responsabilité civile. Paris: Dalloz.

Reyes, Yesid (2005). Imputación objetiva. $3^{\mathrm{a}}$ edición. Bogotá: Temis.

Ripert, Georges y Jean Boulagner (1965). Tratado de derecho civil, según el Tratado de Planiol. (trad.) Delia García Daireaux. Buenos Aires: La Ley, tomo IV: Las obligaciones ( $2^{\mathrm{a}}$ parte).

Roxin, Claus (1997). Derecho penal. Parte general. (trad.) de la $2^{\text {a }}$ edición alemana por Diego Luzón Peña, Miguel Díaz y García Conlledo y Javier de Vicente Remesal. Madrid: Civitas, tomo I: Fundamentos. La estructura de la teoría del delito.

Salvador Coderch, Pablo, Nuno Garoupa y Carlos Gómez Ligüerre (2005). "El círculo de responsables". Indret, n. 309.

Salvador Coderch, Pablo, Sonia Ramos González, Álvaro Luna Yerga y Juan Antonio Ruiz García (2004). "El Derecho de daños hoy: características diferenciales", en José Manuel González Porras y Fernando Pedro MénDEZ GonzÁlez (coords.). Libro homenaje al profesor Manuel Albaladejo García. Murcia: Colegio de Registradores de la Propiedad y Mercantes de España, Universidad de Murcia.

SAn Martín Neira, Lilian (2014). "La reducción del resarcimiento por culpa de la víctima. Reflexiones a la luz del análisis de algunas fuentes romanas". Revista de Derecho Privado Universidad Externado, n. ${ }^{\circ} 27$.

SAn Martín NeIRA, Lilian (2016). "La frontera entre culpa exclusiva y concurrente de la víctima en la producción del daño a la luz de la jurisprudencia chilena”. Revista Chilena de Derecho Privado, n. ${ }^{\circ} 27$.

SAn Martín Neira, Lilian (2018). La culpa de la víctima en la responsabilidad civil. Santiago: Der Ediciones.

Trimarchi, Pietro (1961). Rischio e responsabilità oggettiva. Milano: Giuffrè.

Trimarchi, Pietro (1967). Causalitá e danno. Milano: Giuffrè.

Trimarchi, Pietro (2017). La Responsabilitá Civile: atti illecitti, rischio, danno. Milano: Giuffré.

Viney, Geneviéve et Patrice Jourdain (2013). Les conditions de la responsabilité, $4^{\mathrm{e}}$ édition. Paris: LGDJ.

WEINRIB, Ernest (2013). "Responsabilidad extracontractual como justicia correctiva”, en Carlos Bernal Pulido y Jorge Fabra Zamora (eds.). La filosofía de la responsabilidad civil. (trad.) por Jorge Fabra Zamora. Bogotá: Universidad del Externado.

Welzel, Hans (2002). Derecho penal alemán, Parte general. $4^{\mathrm{a}}$ edición, $11^{\mathrm{a}}$ edición en alemán. (trad.) Juan Bustos Ramírez y Sergio Yáñez Pérez. Santiago: Editorial Jurídica de Chile.

Wrigth, Richard (1985). "Causation in Tort Law". California Law Review, volume 73. 
WRIGTH, Richard (1988). "Causation, responsability, risk, probability, naked statistics, and proof: pruning the bramble busch by clarifying the concepts". Iowa Law Review, n. ${ }^{\circ} 73$.

WRIGTH, Richard (2008). "Liability por possible wrongs: causation, statitiscal probability and the burden of proof, in Symposium, the frontiers of Tort Law". Loyola of Los Angeles Law Review, volumen 41.

ZiPURSKY, Benjamin (1998). "Rights, Wrongs and Recourse in the Law of Torts". Vanderbilt Law Review, vol. 51.

ZiPURSKY, Benjamin (2013). "La filosofía de la responsabilidad extracontractual: entre lo esotérico y lo banal", en Carlos Bernal Pulido y Jorge FABRA Zamora (eds.). La filosofía de la responsabilidad civil. (trad.) por Jorge Fabra Zamora. Bogotá: Universidad del Externado.

SiglaS y ABREVIaTURAS

\author{
AA.VV. autores varios \\ CEDAM Casa Editora Dott. Antonio Milani \\ coord. coordinador \\ coords. coordinadores \\ dirs. directores \\ D. Digesto \\ ed. editor a veces edición \\ eds. editores \\ Fondecyt Fondo Nacional de Desarrollo Cien- \\ tífico y Tecnológico \\ $\mathrm{km}$ kilómetros \\ LGDJ Libraire Genwrale de Droit Juris \\ n. ${ }^{\circ}$ a veces $\mathrm{N}^{\mathrm{O}}$ número \\ p. página \\ pp. páginas \\ ss. siguientes \\ trad. traducción \\ UTET Unione Tipografica-Editrice Torine- \\ se
}

